\title{
Epilepsi som stigma - ond, hellig eller gal?
}

\author{
Forestillinger som for oss fremstår som merkelige, har preget synet på epilepsi gjennom hele vår historie. \\ En rekke kreative, men oftest ineffektive behandlingsmetoder har vært forsøkt.
}

Eldre skrifter vitner om at personer med epileptiske anfall har vært diskriminert gjennom hele vår historie. Vi kan vanskelig sette oss inn i hvordan det var å leve med slike anfall $\mathrm{i}$ en tid da man trodde disse var forårsaket av onde ånder og at åndene kunne påvirke eller smitte andre (1).

En kjent nevrolog har hevdet at «epilepsihistorien kan oppsummeres som 4000 år med ignoranse, mistenkeliggjøring og stigma, etterfulgt av 100 år med kunnskap, mistenkeliggjøring og stigma» (2). I dagens Norge forteller både barn og voksne med epilepsi om utestenging på grunn av skepsis og frykt i samfunnet. Mytene rundt epilepsi er svært seiglivede og mange av dem lever fortsatt (3). Leger og helsepersonell bør avmystifisere epilepsi og slik bedre pasientenes livskvalitet.

\section{Mange betegnelser}

Epilepsi har gjennom historien hatt mange navn. Selve ordet epilepsi ble introdusert av Hippokrates og er utledet fra gresk, «å gripe, ta, ta tak i».

I Norge har mange betegnelser vært i bruk: den hellige sykdom, den store sykdom, fallesyke, fallsott, brotfall, fang, fangkrampe, ilske, brot, krampeslag, slau, begavning, den slemme/onde sykdom og månesyke (4).

Ordet «fallesyke» henspiller på troen på at man under anfall falt til jorden i retning av helvete og djevelen (5). «Fang» eller «fangkrampe» viser til troen om at de underjordiske tar fang eller favntak, og at krampene var et forsøk på å fri seg fra dette taket (4).

«Begavning» vitnet om at epilepsi også var assosiert med spesielle evner, blant annet evnen til å helbrede andre. I Norge er Knut Rasmussen Nordgarden (1792-1876) kanskje den mest kjente. Han var bosatt i Vestre Gausdal og ble kalt Vis-Knut. Til ham kom folk langveis fra for å bli kurert for sykdom (6) (fig 1).

«Den hellige sykdom» ble brukt fordi man også trodde personer med epilepsi hadde kontakt med Gud. Et eksempel er Christina the Astonishing (1150-1224), eller Christina Mirabilis som hun også ble kalt. Hun var en fattig og foreldreløs bondejente fra Belgia som hadde et alvorlig epileptisk anfall som ung. Etter anfallet trodde man hun var død og begravet henne. Plutselig ropte Christina ut: «Stanken av menneskets synd er mer enn jeg kan holde ut!». Senere i livet utførte hun en rekke mirakuløse handlinger. Hun er blitt et symbol på menneskelig lidelse og på at man selv må kjempe mot stigma og fordommer (7).

«Månesyke» (lunatic $=$ sinnssyk) stammer fra en forestilling om at psykiske forstyrrelser var nær knyttet til månefasene. I Norge hadde vi en tid diagnosen insania epileptica (epileptisk sinnssykdom). I 1925 var 223 personer innlagt i norske sykehus med den diagnosen (8). Begrepet «hysteroepilepsi» ble etablert av den franske nevrologen Jean Martin Charcot for å beskrive anfall som nevrotiske pasienter fikk etter at de hadde observert anfall hos pasienter med epilepsi på samme avdeling.

\section{Årsaksforklaringene var mange}

I antikken ble epilepsi ansett som en hellig sykdom som var påført av gudene. Behandlingen besto av offerhandlinger og religiøse ritualer under ledelse av prester.

I mange århundrer trodde man epilepsi var forårsaket av onde ånder, djevler og demoner («morbus daemonicus»). Epilepsi var også knyttet til hekseri. I en håndbok fra 1494, Malleus Maleficarum (Heksehammeren), blir det hevdet at hekser hadde særlige karakteristika, blant annet epileptiske anfall (9).

Folkefortellinger fra Norden på 1600-, 1700- og 1800-tallet viser at epilepsi ble sett på som resultat av hendelser i svangerskapet. Den gravide måtte unngå å være «uaktsom»-hvis ikke fikk barnet fallesyke (1). Gravide kvinner måtte vokte seg for alt som hadde falt sammen. Eksempelvis måtte man ikke trå over gjerder som hadde falt sammen, man måtte ikke være vitne til noen som demonterte vever og heller ikke miste gjenstander. Hvis man så noen som falt, måtte man for all del hjelpe dem opp igjen for å unngå de magiske kreftene (1). I bygda Slätthög i Småland blir det fortalt at man måtte passe seg for å kaste barnets badevann rett ut i naturen. Da ville vannet berøre de underjordiske vettene som senere hevnet seg ved å påføre barnet epilepsi (1).

Det var også en utbredt oppfatning at epilepsi kunne være Guds straff for egne eller forfedrenes ugjerninger.
Mange ulike behandlingsmetoder Innføring av kristendommen forsterket troen på helbredelse ved hjelp av religiøse ritualer. I Det nye testamente fremgår det at Jesus helbredet en gutt med «månesyke», dvs. epilepsi: «Og Jesus talte myndig til ham, den onde ånden fór ut, og gutten ble frisk i samme stund» (10). De mest brukte behandlingsformer var bønn, faste, offerhandlinger og eksorsisme (djevleutdrivelse). Man tilba også enkelte helgener.

«Å sette sykdom i jord» var et vanlig behandlingsprinsipp (4). For å lede sykdommer til jorden skulle man for eksempel legge en arm som rykket under anfall, mot jorden. «Smyging» kunne også virke mot anfall, dvs. å trekke personen gjennom en åpning i naturen, for eksempel gjennom en steinhule eller et hult tre (fig 2).

Man trodde også at en amulett eller pose med tørkede dyreorganer rundt halsen kunne virke helbredende. Andre behandlingsformer var kastrasjon, årelating, blodigler og kraniotomi (for å slippe ut onde ånder), aske fra brente klær man hadde på seg under anfall, urter, ulike metaller, blod fra både dyr og mennesker, urin og oppmalte menneskeskaller (fig 3). Metodene var

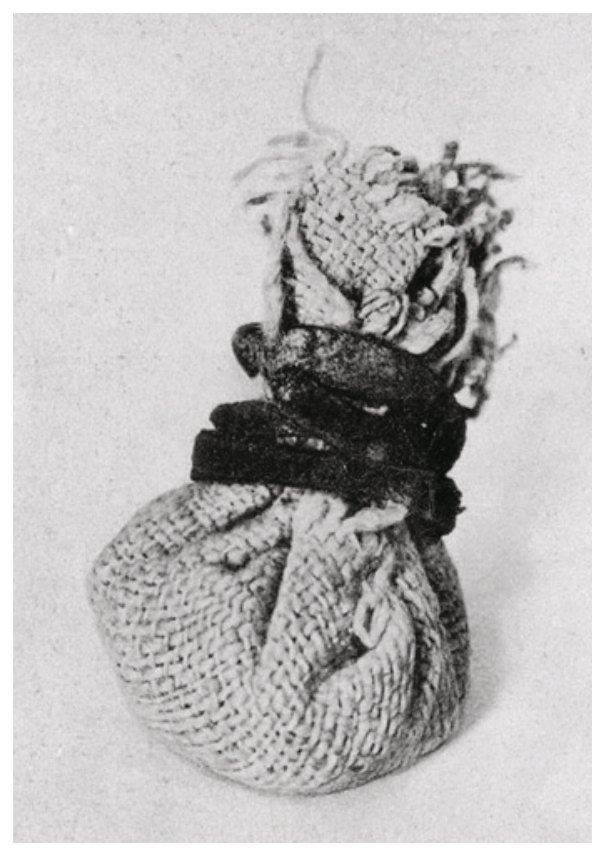

Figur 1 Trollpose, datert 1885. Man benyttet poser med virksomme ingredienser som man bar på seg. ofte rundt halsen (1, s. 86) 
i beste fall helt uvirksomme, i verste fall skadelige (5).

I boktrykkerkunstens spede begynnelse var urtebøker viktige. Bøkene var gjerne velsignet av den lokale biskopen som presiserte at «denne urten hjelper - om Gud vil» (11).

Bromsalter i epilepsibehandlingen ble innført i Norge i 1930-årene og var fortsatt i bruk rundt 1950. Saltene var ofte bakt inn i brød (12). Det til tross for at andre og mer virksomme legemidler var blitt introdusert. Bromsalter hadde en anfallsreduserende effekt, men de kunne gi omfattende bivirkninger, for eksempel store byller på huden. Historien viser dessverre at om en behandlingsmetode først er blitt utbredt, kan det ta lang tid før man stopper å bruke den selv om den har vist seg å være skadelig (5).

Lobotomi som behandlingsmetode ble benyttet ved norske psykiatriske sykehus i 1940-årene og frem til 1957. Lite kjent er det at også personer med epilepsi fikk denne behandlingen som førte til mer eller mindre omfattende hjerneskader. En del av dem som ikke hadde epilepsi fra før, fikk postoperativ epilepsi i tillegg til andre tegn til frontale skader (13).

\section{«Morderisk og moralsk fordervet»} Gjennom mange århundrer ble enkelte former for epileptiske anfall, for eksempel komplekse partielle anfall med fjernhet og underlig atferd, tolket som galskap. Ved opprettelsen av psykiatriske asyler på 1800-tallet ble derfor mange med epilepsi plassert der.

På slutten av 1800-tallet mente man at epilepsi var en degenerativ sykdom. "Ved den saakaldte epileptiske Degenerasjon utvikler der sig sjælelig Uligevækt, moralske Defekter, Løgnaktighed, Holdningsløshed, ofte Drikfældighed og Tilbøylighed til Vagabonderen» (14).

Dell har beskrevet personlighetstrekk hos personer med epilepsi; pasienten var «gal og ond med tilbøyelighet til uforutsigbare anfall av vold og galskap, kanskje morderiske tendenser og sikkert moralsk fordervelse» (15). Hyperreligiøsitet, hypergrafi og hyposeksualitet er også blitt ansett som en del av den epileptiske personligheten (16).

Med det sosiale stigmaet som fulgte med diagnosen har det til alle tider vært vanskelig for personer med epilepsi å finne arbeid. Mange måtte tigge, andre tok strøjobber eller gikk på legd mellom gårder (17). På verdensbasis er arbeidsledigheten fortsatt høy blant personer med epilepsi, og diskriminering på arbeidsmarkedet er fortsatt vanlig (18).

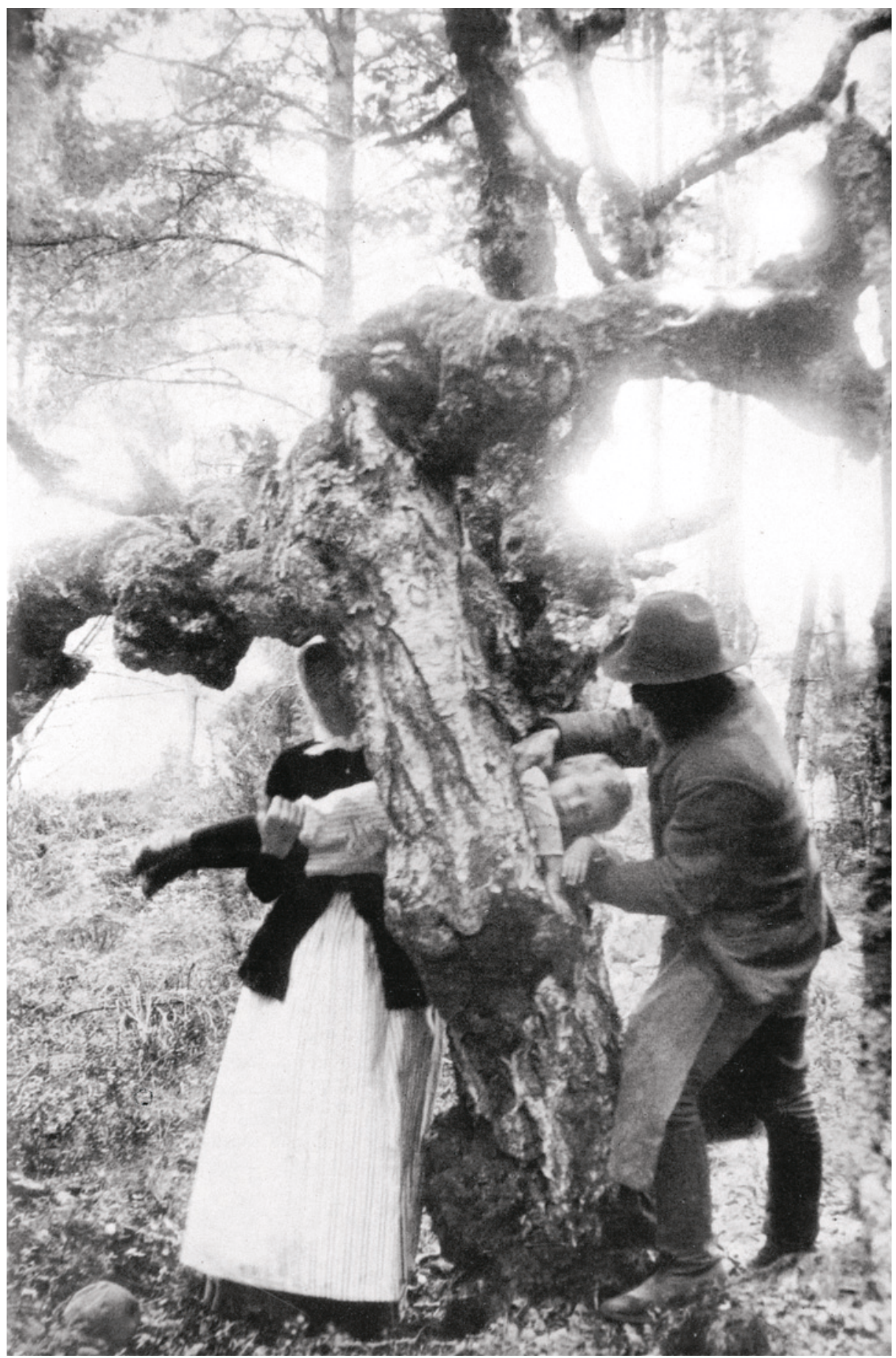

Figur 2 Smyging var en av mange metoder som ble brukt for å kurere epilepsi. Her trekker man barnet gjennom en åpning i et tre, foto fra 1922 (1, s. 31).

\section{Genetisk rensing og diskriminering}

Den tyske psykiateren Hans Berger, som oppdaget elektroencefalografi (EEG)

i 1924, var den første til å vise at epilepsi var forbundet med unormal elektrisk aktivitet i hjernen. Det bidro dessverre ikke til noen stor endring av vanlige folks syn på epilepsi.

I Tyskland antok man i 1920-årene at $80 \%$ av dem som levde i epilepsikoloniene hadde en nedarvet epilepsiform (19). Den tiden var preget av teorier om rasehygiene. Personer med arvelige lidelser, inkludert epilepsi, måtte ikke få barn. Man satte i gang tvangssterilisering og utryddelse av barn under tre år med funksjonshemninger. I praksis ble alle funksjonshemmede opp til 17 års alder drept (19).

I perioden $1907-64$ ble totalt rundt 60000 personer med epilepsi sterilisert, deriblant rundt 30 i Norge (20). I Norge 


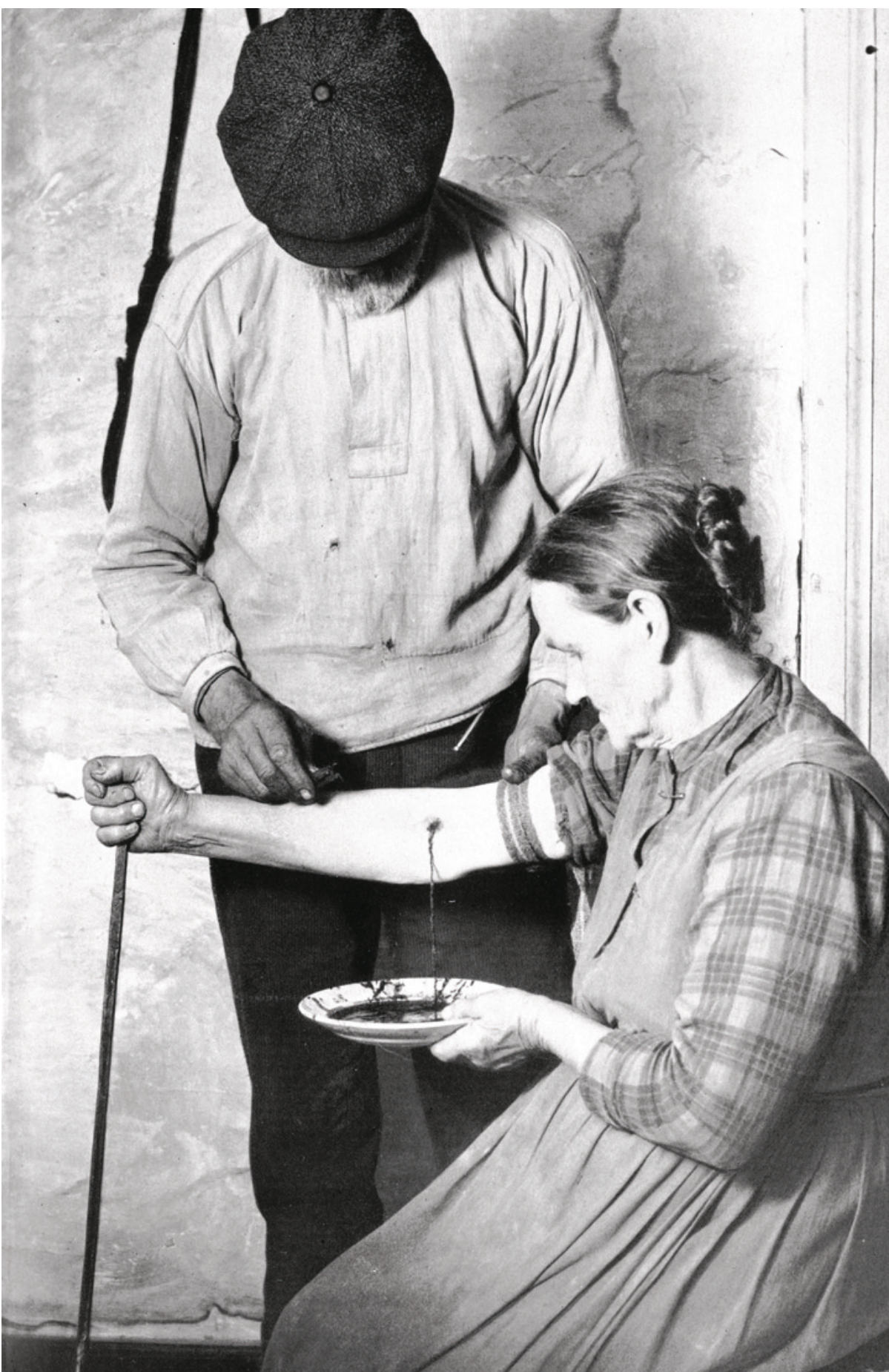

Figur 3 Årelating i Värmland, 1918. Man benyttet årelating som behandlingsmetode for epilepsi. Å drikke blod fra mennesker eller dyr var også en mye anvendt behandlingsmetode (1, s. 293)

hadde man inntil 1969 plikt om å opplyse om sin epilepsi ved inngåelse av ekteskap. Ekteskapet kunne oppløses dersom slik informasjon ble holdt tilbake (21).

Endring av myter og misoppfatninger om epilepsi har gått sakte fremover. Fremdeles opplever mange fordommer som er en tilleggsbelastning som er like vanskelig å leve med som epilepsien i seg selv.

\section{Mia Tuft}

mia.tuft@ous-hf.no

Kompetansesenter for sjeldne epilepsirelaterte diagnoser

Kvinne- og barneklinikken

Oslo universitetssykehus

\section{Karl 0. Nakken}

Spesialsykehuset for epilepsi

Klinikk for kirurgi og nevrofag

Oslo universitetssykehus
Mia Tuft (f. 1972) er spesialist i nevropsykologi og har skrevet barnebøker om å leve med epilepsi.

Forfatter har fylt ut ICMJE-skjemaet og oppgir ingen interessekonflikter.

Karl Otto Nakken (f. 1945) er spesialist i nevrologi, med spesialkompetanse innen epileptologi, dr.med. og medisinsk ansvarlig ved Spesialsykehuset for epilepsi.

Forfatter har fylt ut ICMJE-skjemaet og oppgir ingen interessekonflikter.

\section{Litteratur}

1. Tillhagen CH. Folklig läkekonst. 2. opplag. Stockholm: LTs Förlag, 1962.

2. Kale R. Bringing epilepsy out of the shadows BMJ 1997: 315: 2-3.

3. Nakken KO, Lossius M. Fordommer og myter om epilepsi. Aftenposten 2.4.2013. www.aftenposten no/meninger/kronikker/Fordommer-og-myter-omepilepsi-7162579.html (3.11.2014).

4. Reicborn-Kjennerud I. Vår gamle trolldomsmedisin. Bd. 5. Oslo: Jacob Dybwad, 1947

5. Temkin 0. The falling sickness. 2. utg. Baltimore, MD: Johns Hopkins University Press, 1971

6. Skard J. Vis-Knut. Svatsum: Vis-Knut-heimens vener, 1984.

7. Enlightened Catholicism

http://enlightenedcatholicism-colkoch.blogspot. no/2008/07/feast-day-of-st-christina-astonishing. html (3.11.2014).

8. Norges offentlige statistikk. VIII. 17. Sinnsykeasylenes virksomhet 1925. Efter de fra asylene innkomne årsberetninger. Utarbeidet av overlægen for sinnsykevesenet. Oslo: Aschehoug \& co, 1927.

9. Summers M. red. Malleus maleficarum. London: John Rodker, 1928

10. Nettbibelen. Matteusevangeliet. www.bibel.no/ Nettbibelen?query=SyXGjvFYqNKodwy23YKngf CMSq/5yOePD3IJEgiloPFIZzf8TBz66g = = (4.9.2014)

11. Månsson A. Den herlige urteboken fra 1628. Oslo: Kolibri, 1998.

12. Hem E. Brød i behandlingen av epilepsi. Tidsskr Nor Legeforen 2010; 130: 1995

13. Isdahl PJ. Grepet om hjernen. Fra lobotomiens historie. Oslo: Aschehoug Argument, 1993.

14. Arts N. Epilepsy through the ages. An anthology of classic writings on epilepsy. Alphen aan den Rijn: Van Zuiden Communications, 2001.

15. Dell JL. Social dimensions of epilepsy, stigma and response. I: Whitman S, Hermann BP, red. Psychopatology in epilepsy, social dimensions. New York, NY: Oxford University Press, 1986: 185-210.

16. Waxman SG, Geschwind N. The interictal behavior syndrome of temporal lobe epilepsy. Arch Gen Psychiatry 1975; 32: 1580-6.

17. Nakken KO. Epilepsi. 2. utg. Oslo: Cappelen Akademiske, 2010.

18. Camfield PR, Camfield CS. What happens to children with epilepsy when they become adults? Some facts and opinions. Pediatr Neurol 2014; 51: 17-23.

19. German Epilepsy Museum. Kork. www.epilepsiemuseum.de/english/ (3.11.2014).

20. Dell JL. Social dimensions of epilepsy, stigma and response. I: Whitman S, Hermann BP, red. Psychopatology in epilepsy, social dimensions. New York, NY: Oxford University Press, 1986: 185-210.

21. Lov 31. Mai $1918 \mathrm{nr}$. 2 om indgaaelse og opløsning av egteskap, kap 4, § 35. www.hoelseth.com/acts/ act19180531-002.html\#kap4 (30.10.2014).

Mottatt 4.7. 2014, første revisjon innsendt 9.9. 2014, godkjent 6.11. 2014. Redaktør: Anne Kveim Lie. 